\section{LA-UR-99-= 1393}

Title:

Author(s):

Submitted to:
G.O. Bolme, T.W. Hardek, L.D. Hansborough, D.J.

Hodgkins, D.R. Keffeler, J.D. Sherman, H.V. Smith, R.R. Stevens, L.M. Young, T.J. Zaugg (LANL, Los Alamos, NM)

A.H. Arvin, A.S. Bolt, M.C. Richards (SRS, Aiken, SC)

P.P. Balleyguier (CEA-Bruyeres le Chatel, France)

J.H. Kamperschroer (General Atomics, San Diego, CA)

1999 Particle Accelerator Conference

New York City

March 29 - April 2, 1999

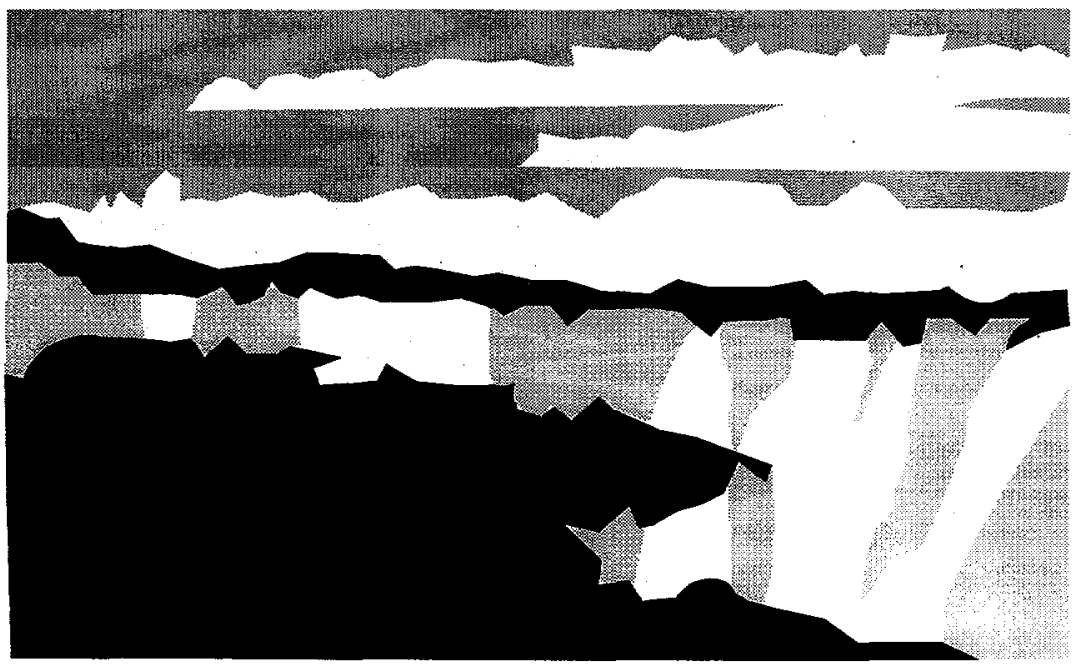

Los Alamos National Laboratory, an affirmative action/equal opportunity employer, is operated by the University of California for the U.S. Department of Energy under contract W-7405-ENG-36. By acceptance of this article, the publisher recognizes that the U.S. Government retains a nonexclusive, royalty-free license to publish or reproduce the published form of this contribution or to allow others to do so, for U.S. Government purposes. The Los Alamos National Laboratory requests that the publisher identify this article as work performed under the auspices of the U.S. Department of Energy. 


\section{DISCLAIMER}

This report was prepared as an account of work sponsored by an agency of the United States Government. Neither the United States Government nor any agency thereof, nor any of their employees, make any warranty, express or implied, or assumes any legal liability or responsibility for the accuracy, completeness, or usefulness of any information, apparatus, product, or process disclosed, or represents that its use would not infringe privately owned rights. Reference herein to any specific commercial product, process, or service by trade name, trademark, manufacturer, or otherwise does not necessarily constitute or imply its endorsement, recommendation, or favoring by the United States Government or any agency thereof. The views and opinions of authors expressed herein do not necessarily state or reflect those of the United States Government or any agency thereof. 


\section{DISCLAIMER}

Portions of this document may be illegible in electronic image products. Images are produced from the best available original document. 


\title{
Proton Beam Verification Using rf Power Measurement Data for a cw Radio Frequency Quadrupole LINAC ${ }^{*}$
}

\author{
G.O. Bolme, L.D. Hansborough, T.W. Hardek, D.J. Hodgkins, D.R. Keffeler, J.D. Sherman, \\ H.V. Smith, R.R. Stevens, L.M. Young, T.J. Zaugg, LANL, Los Alamos, NM \\ A.H. Arvin, A.S. Bolt, M.C. Richards, Savannah River Site, Aiken, SC \\ P.P. Balleyguier, CEA-Bruyeres le Chatel, France \\ J.H. Kamperschroer, GA, San Diego, CA
}

\section{Abstract}

A cw radio frequency quadrupole (RFQ) LINAC section and klystrode based if system was obtained from the Chalk River Laboratories and was recommissioned at LANL to conduct demonstration proton beam experiments in support of a spallation neutron source driver for tritium production. A variation of the Low Energy Demonstration Accelerator (LEDA) proton injector, modified to operate at $50 \mathrm{keV}$, was mated to the RFQ and was operated to support the high current (up to $100 \mathrm{~mA}$ ), proton beam advance studies for the Accelerator Production of Tritium (APT) program. Detailed measurements and calibrations of the RFQ at both low and high power provided the corroborating data to other available beam measurements for verification of the accelerator design.

\section{INTRODUCTION}

The Chalk River Injector Test Stand (CRITS) was the LANL designation given to a proton accelerator designed, built, and originally commissioned at the Chalk River Laboratories (CRL) in Canada [1]. The CRITS accelerator apparatus includes a 1.25 MeV RFQ accelerator structure and a prototype klystrode-based if system for powering the RFQ. An earlier independent study at LANL, utilizing the RFQ, focussed on the high-power operation of the rf structure [2].

The LEDA program has the objective of developing a high-current, cw injector and the initial of accelerating structures for APT. The LEDA injector is. comprised of the proton ion source and a Low Energy Beam Transport (LEBT) section to the RFQ. A $75 \mathrm{kV}$, cw proton ion source was developed for LEDA and has produced a proton beam with measured current and emittance meeting program requirements. A state-of-the-art LEBT was designed and built to match the ion source beam to the LEDA RFQ [3].

The functionality of an injector is best confirmed by injecting its beam into an RFQ. The availability of the CRITS RFQ provided the opportunity for an initial shakedown of the LEDA injector prior to installing the injector as a LEDA subsystem. The modification of the ion source to $50 \mathrm{kV}$ and adaptation of the LEBT exit

\footnotetext{
*Work supported by the US Department of Energy.
}

section to the CRITS RFQ made the LEDA injector/CRITS RFQ configuration a realistic testbed for this injector development. Furthermore, this configuration also supported RFQ experiments to evaluate the system modeling codes and to learn the details of $\mathrm{cw}$ RFQ operations. Figure 1 shows the full beamline used in this project.

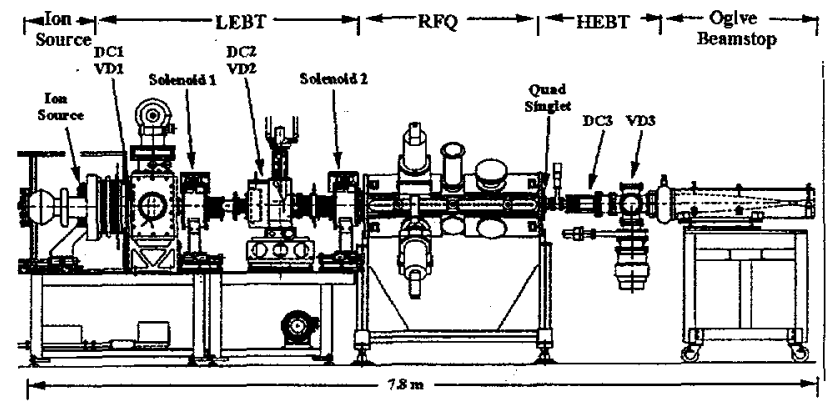

Figure 1. The LEDA Injector/CRITS RFQ beamline.

In order to meet the project objectives, the RFQ specific studies focussed on verifying the RFQ field configuration, successfully operating the RFQ at high power, verifying the accelerating fields in the RFQ, and accelerating proton beam from the modified LEDA injector.

\section{RFQ FIELD DISTRIBUTIONS}

Although the $\mathrm{Q}$ and resonant frequency of the RFQ were close to the expected values following shipment of the RFQ from CRL, the verification of the modeling codes mandated that the field distribution in the structure be confirmed. A perturbation measurement of the cavity fields was made by inserting a probe through the various vacuum pumping holes in each of the quadrants, and the dipole field contributions to the quadrupole fields were calculated from these measurements. The uncorrected dipole fields across quadrants 1 and 3 (dipole 1) were measured to be up to $14 \%$ of the quadrupole field and up to $8 \%$ across quadrants 2 and 4 (dipole.2). The dipole field distribution along the RFQ length indicated that the vane coupling rings near the ends held the distribution close to the desired quadrupole configuration, thus, dipole field reduction at the center should achieve an acceptable field pattern in the RFQ. Adjustment of movable tuners in quadrants 2 and 4 and modification of the fixed tuner in quadrant 3 corrected the field distribution to less than $4 \%$ 
dipole contribution. This was considered acceptable for the beam studies. Figures 2 and 3 display the corrected and uncorrected dipole contributions for dipoles 1 and 2 respectively.

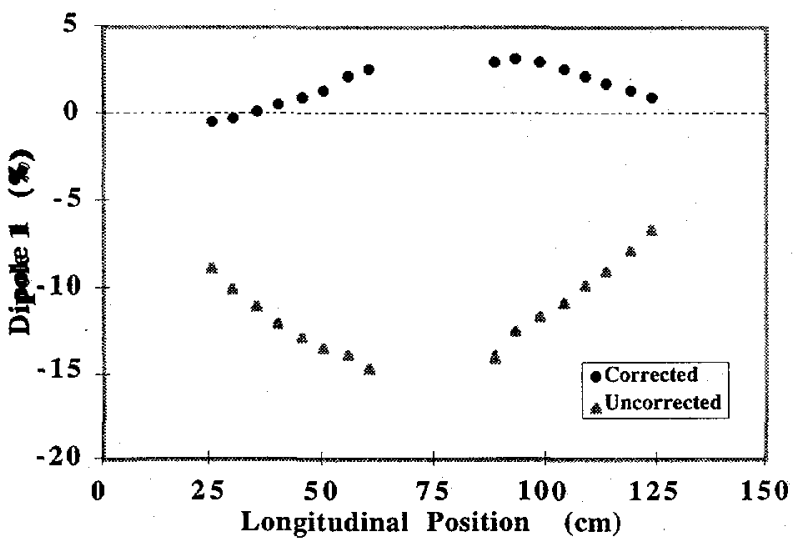

Figure 2. Dipole 1 Contribution to the quadrupole field distribution.

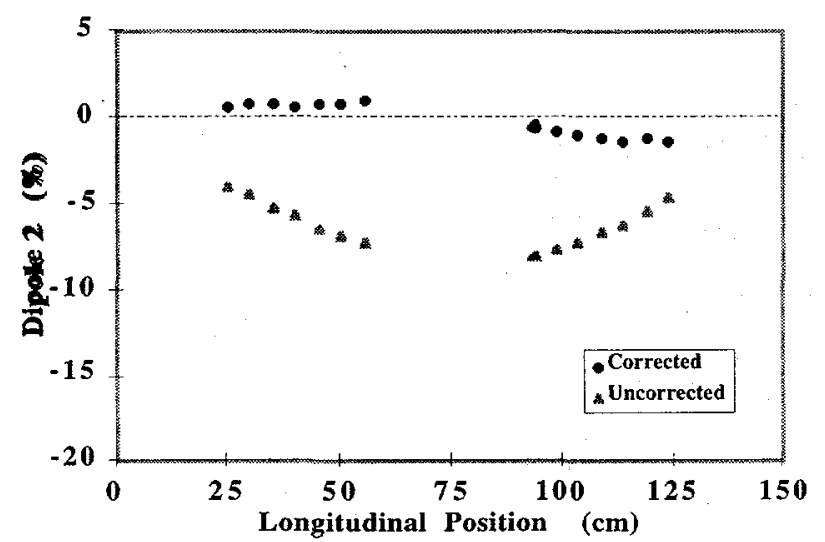

Figure 3. Dipole 2 Contribution to the quadrupole field distribution.

\section{CALIBRATIONS}

Accurate predictions of the acceleration and focusing fields require consistent measurements of the RFQ response to $\mathrm{rf}$ power. The $\mathrm{RFQ}$ driveline coupling and $\mathrm{Q}$ were measured using a Hewlett Packard 8753 Network Analyzer. The driveline coupling was verified from subsequent high power measurements. The $Q$ was measured using reflected power; transmitted bandwidth, and transmitted delta phase techniques as shown in Figures 4,5 . and 6. The close agreement in $Q$ measurements is shown in Table 1.

Table 1: Measured RFQ Q values

\begin{tabular}{|l|c|c|}
\hline \multicolumn{1}{|c|}{ Meaurement } & Loaded Q & Unloaded Q \\
\hline Reflected Power & 2650 & 6780 \\
\hline $\begin{array}{l}\text { Transmitted } \\
\text { Bandwidth }\end{array}$ & 6760 \\
\hline $\begin{array}{l}\text { Transmitted Delta } \\
\text { Phase }\end{array}$ & 2640 & 6720 \\
\hline
\end{tabular}

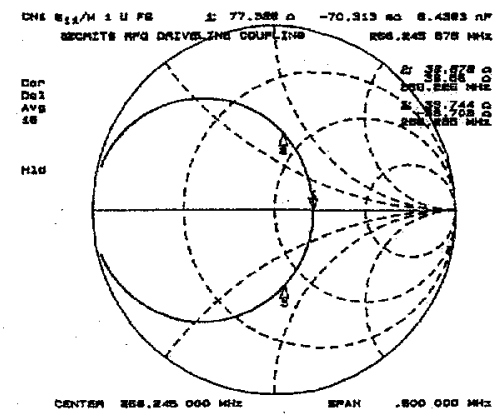

Figure 4. Reflected power Q measurement.

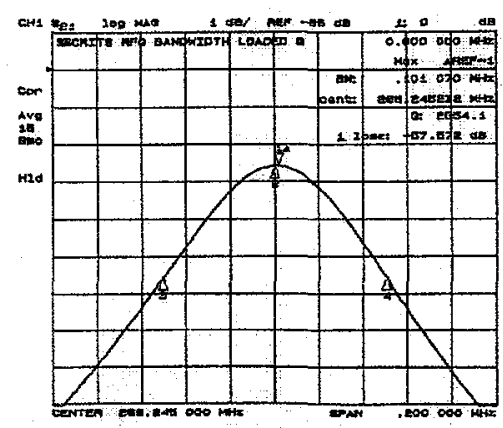

Figure 5. Transmitted bandwidth Q measurement.

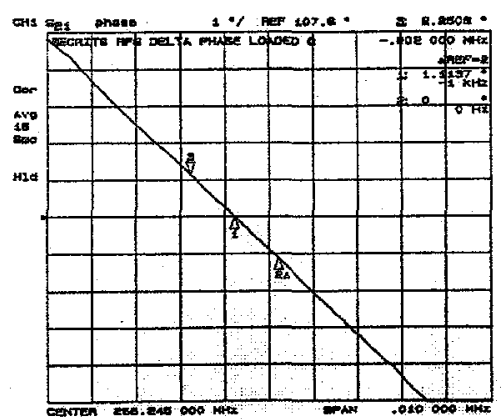

Figure 6. Transmitted delta phase $\mathrm{Q}$ measurement.

The calibrations of the field sampling loops were also completed using a Hewlett Packard 8753 Network Analyzer, and the rf signals from these loops at high power were monitored using power meters and oscilloscope measurements of the unrectified if signals. Again, the measurement of forward, reflected, and RFQ cavity powers by Hewlett Packard 438 A power meters and a Tektronix $2465 \mathrm{~A}$ oscilloscope provided redundancy in the high-power measurements.

\section{HIGH-POWER FIELD LEVEL VERIFICATION}

The RFQ was conditioned to high power based on the SUPERFISH prediction of the design power level. Highpower measurements of the actual field level were made using the $\mathrm{X}$-ray endpoint method [4], a technique pioneered 
by accelerator scientists at CRL. Measurements made throughout the duration of the proton beam studies verified that the peak intervane gap voltage tracked the measured power levels according to the expected square root dependency, and comparisons of the power meter to the oscilloscope measurements confirm an estimated $\pm 5 \%$ accuracy to the power measurements. Furthermore, the field levels were measured to be the same when the proton beam was being accelerated by the RFQ. Figure 7 displays the gap voltage data and the curve used to project the peak intervane gap voltage as a function of the measured power.

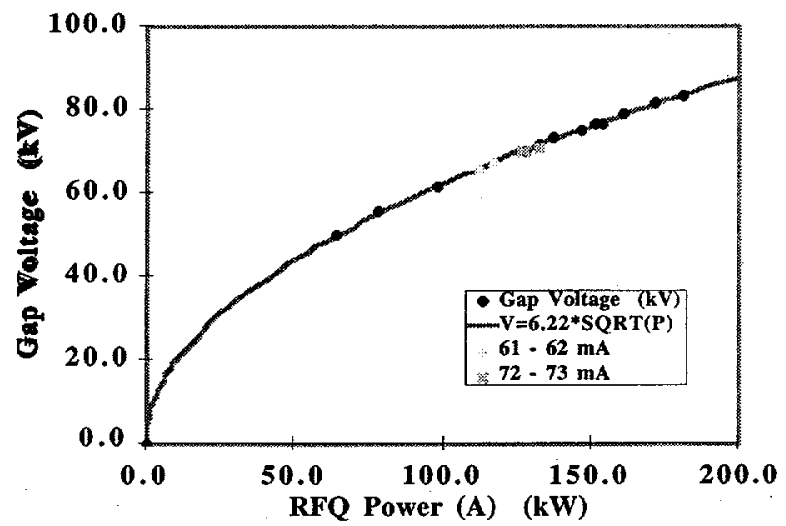

Figure 7. Peak intervane gap voltage as a function of RFQ cavity power.

\section{PROTON BEAM MEASUREMENTS}

The proton beam studies with the RFQ proceeded cautiously by increasing current only as the injector match to the RFQ could be confirmed by the beam transmission. The desired field level for the RFQ was set from the $\mathrm{x}$-ray endpoint measurement, but a measurement of beam transmission as a function of the RFQ cavity power was also used to confirm the expected behavior. As expected, a knee in the transmission curve was observed below the design field level.

As a separate check for accelerated beam, the incident power difference and beam stop calorimetry were compared to the expected beam power under the assumption that the entire proton beam was accelerated. This assumption is known to be false but allows us to compare the beam transmission data with the two beam power measurements using the same units. These data are shown in Figure 8. The rf incident power difference and calorimetry measurements of the beam as a function of RFQ cavity power show a discrepancy in absolute calibrations, but the knee in the curve for both measurements agree. The disagreement in predicted beam powers by the two diagnostic methods is probably due to the identified errors in the rf power measurements and errors in beam stop calorimetry. The lower RFQ cavity power correlated with the knee for beam transmission compared with the other power measurements indicates that beam is transmitted even though it is not accelerated.

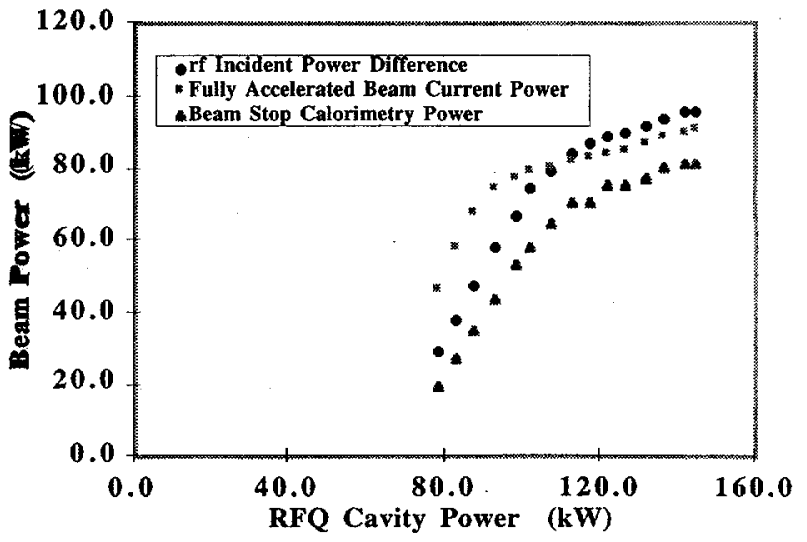

Figure 7. Peak intervane gap voltage as a function of RFQ cavity power.

\section{SUMMARY}

The CRITS RFQ proved to be an excellent test device for checking out all components of the injector. By optimizing the current through the RFQ, all injector systems demonstrated that they could operate across the required parameter space. The procedures developed in during the CRITS RFQ beam operations has expedited the commissioning of LEDA. The successful transmission of beam currents with good agreement to the simulations [5] also provides confidence in the codes as we proceed into future projects.

\section{ACKNOWLEDGMENTS}

With the conclusion of the RFQ studies using the CRITS RFQ, we would like to thank and express our gratitude to the personnel at Chalk River Laboratories who designed, fabricated, assembled, and commissioned this accelerator section under the RFQ1 program. The technical progress made in our programs is a result of their groundbreaking efforts and the follow-on studies done with the equipment developed at their laboratory.

\section{REFERENCES}

$1 \mathrm{~J} . Y$. Sheikh, et al., "Operation of a High-Power CW Klystrode with the RFQ1 Facility", Proc. 1993 Particle Accel. Conf., IEEE 93CH3279-7, p. 1175 .

2 G.O. Bolme, et al., "High-Power RF Operations Studies with the CRITS RFQ", Proc: 1995 Particle Accel. Conf., IEEE 95CH35843, p. 923.

[3] J. Sherman, et al., Rev. Sci. Instrum. 69 (1998) 1003-1008.

[4] G.O. Bolme, et al., "Measurement of RF Accelerator Cavity Field Levels at High Power from X-ray Emissions" in Proceedings of the 1990 Linear Accelerator Conference, LA-12004-C,219 (1990).

[5] H.V. Smith, et al., "Comparison of Beam Simulations with Measurements for a 1.25-MeV, CW RFQ" in Proceedings of the 1998 Linear Accelerator Conference. 